\title{
QUALIDADE FISIOLÓGICA DE SEMENTES DE MILHO-DOCE BR 400 (BT) EM FUNÇÃO DO TEOR DE ÁGUA NA COLHEITA E DA TEMPERATURA DE SECAGEM ${ }^{1}$
}

\author{
JOSIANE MARLLE GUISCEM², JOÃO NAKAGAWA³ E CLAUDEMIR ZUCARELI ${ }^{4}$
}

\begin{abstract}
RESUMO - O objetivo deste estudo foi avaliar a qualidade fisiológica das sementes de milhodoce em função do teor de água na colheita e da temperatura de secagem em espiga. O experimento foi instalado na área experimental da FCA/Unesp, Botucatu-SP. Utilizou-se a cultivar BR $400(b t)$ 'Super doce'. O delineamento experimental empregado foi o de blocos ao acaso com seis repetições, constituindo os tratamentos as épocas de colheitas. As colheitas das espigas foram iniciadas após a maturidade fisiológica; após despalhadas e divididas em duas porções, as espigas foram submetidas a secagem em estufas com circulação forçada nas temperaturas de 30 e $40^{\circ} \mathrm{C}$. Foi utilizada uma testemunha com sementes secadas no campo com $10,1 \%$ de teor de água. Foram determinados os teores de água das sementes, inicial e após a secagem, de todas as colheitas. Após a secagem, as espigas foram debulhadas manualmente, as sementes acondicionadas em saco de papel e armazenadas em condições ambientais de laboratório. As avaliações da qualidade fisiológica das sementes (emergência de plântulas no campo, índice de velocidade de emergência, matéria seca de plântulas, germinação, vigor-primeira contagem do teste de germinação, envelhecimento acelerado, teste de frio, condutividade elétrica e teores de $\mathrm{Ca}, \mathrm{Mg}, \mathrm{K}$ e $\mathrm{Na}$ lixiviados na solução do teste de condutividade elétrica) foram realizadas antes e após seis meses de armazenamento. As sementes de milho-doce cultivar BR 400 (bt), com teor de água igual ou menor do que $35 \%$, podem ser submetidas à secagem em espiga a temperatura de $30 \mathrm{ou} 40^{\circ} \mathrm{C}$, sem perdas significativas em sua qualidade fisiológica.
\end{abstract}

Termos para indexação: sementes, milho-doce, temperatura de secagem, retardamento da colheita, teor de água.

\section{PHYSIOLOGICAL SEED QUALITY OF SWEET CORN AS A FUNCTION OF WATER CONTENT AT HARVEST TIME AND DRYING TEMPERATURES}

\begin{abstract}
The purpose of the present research was to study the physiological seed quality of sweet corn as a function of water content at harvest time and drying temperatures of the ears. Experiments were made in the Agriculture School of São Paulo State University located in Botucatu, São Paulo, Brazil. Ears of sweet corn cultivar, BR 400 Super Sweet (brittle), were harvested at different times, starting at physiological seed maturity and submitted to different drying temperatures $\left(30\right.$ and $40^{\circ} \mathrm{C}$ ) in an air circulation chamber. Field dried seeds, with $10.1 \%$ of water content, were utilized as a control. After drying, ears were shelled and seeds were stored in paper bags under laboratory environmental conditions. Initial water content of seed before and after drying was determined. Physiological seed quality for each harvesting date and drying temperature were analyzed before storage and six months after. The following characteristics were utilized: seedling emergency, speed of seedling emergence, seedling dry matter content, germination, first germination count, accelerated ageing, cold test, electrical conductivity and $\mathrm{Ca}, \mathrm{Mg}, \mathrm{K}$ and $\mathrm{Na}$ lixiviated from
\end{abstract}

\footnotetext{
${ }^{1}$ Aceito para publicação em 31.12.2001; parte integrante da Tese de Doutorado do primeiro autor, em Agronomia na Área de Concentração Agricultura da FCA/UNESP de Botucatu-SP, desenvolvida com recurso da CAPES.

${ }^{2}$ Eng $^{\mathrm{a}}$ Agr ${ }^{\mathrm{a}}$, Dra.; e-mail: jmguiscem@globo.com
}

${ }^{3}$ Prof. Titular Volutário, Depto. Produção Vegetal, FCA/UNESP; Cx. Postal 237, 18603-970, Botucatu-SP; bolsista do CNPq; e-mail: secdamv@fca.unesp.br

${ }^{4} \mathrm{Eng}^{\mathrm{O}} \mathrm{Agr}^{\mathrm{o}}$, Doutorando na Pós-Graduação Agronomia/Agricultura FCA/ UNESP; bolsista da CAPES; e-mail: claudemir@fca.unesp.br 
seeds in the water of the conductivity test. Seeds of the cultivars BR $400(b t)$ with water content of $35 \%$ or less may be submitted to drying temperatures of 30 or $40^{\circ} \mathrm{C}$ without loose physiological quality.

Index terms: seed, sweet corn, drying temperature, moisture content.

\section{INTRODUÇÃO}

Dos vários genes mutantes recessivos de milho-doce que afetam, isoladamente ou em conjunto, o desenvolvimento do endosperma, o tipo Brittle ( $b t)$, no estádio de grãos maduros, produz muitos açúcares em detrimento à produção do amido, provocando um grande decréscimo no carboidrato total. Para Cameron \& Teas (1954), cultivares que possuem esse gene produzem aproximadamente $30 \%$ da quantidade normal de amido. Devido ao elevado nível de açúcares, as cultivares com esse tipo de genótipo são habitualmente denominado de superdoce (Gama, 1997).

Sementes de milho superdoce possuem, em geral, germinação inferior (Waters \& Blanchete, 1983); em função da menor quantidade de amido, a cristalização de açúcares no endosperma e a separação que ocorre entre o aleurona e o pericarpo, durante a desidratação, criam-se espaços internos, fazendo com que as sementes apresentem um aspecto enrugado; em conseqüência disso o pericarpo torna-se mais frágil, mais suscetível a danos e a entrada de patógenos (Douglas et al., 1993).

Todavia não se sabe se o baixo vigor das sementes de milho doce, principalmente as do grupo superdoce, é devido à menor reserva de amido no endosperma ou se o embrião é por si mesmo, geneticamente inferior e incapaz de exibir um alto vigor (McDonald et al., 1994). Segundo Waters \& Blanchatte (1983), a menor porcentagem de emergência das plântulas, em sementes de milho-doce, é devido ao manuseio incorreto, entre outros fatores que reduzem a qualidade das sementes.

Diversos trabalhos têm sido realizados com o objetivo de se estabelecer a melhor época de colheita de sementes de milho-doce, pois a má qualidade das sementes pode ser resultante da colheita prematura.

Churchill \& Andrew (1984) colheram sementes de milho doce $s h-2$ com teor de água entre 37 e $51 \%$, encontrado valores de germinação maiores que $90 \%$, enquanto Bennett et al. (1988), encontraram valores acima de $95 \%$ de germinação em sementes colhidas com teor de água entre 29 e 59\%.

No entanto, o alto teor de água, com que as sementes de milho em espiga são colhidas, faz com que a secagem em secadores estacionários seja imprescindível para reduzir ao teor adequado para o armazenamento. De acordo com Carvalho \& Nakagawa (2000), o elevado teor de água, durante o armazenamento, é uma das principais causas da perda do poder germinativo e do vigor das sementes.

Pode-se aumentar a quantidade de danos nas sementes dependendo da temperatura de secagem utilizada, sendo que a sua intensidade varia com o tipo de manejo e a cultivar, havendo uma tolerância diferencial de sementes de milho a altas temperaturas de secagem, em função do material genético considerado (Navratil \& Burris, 1984).

Segundo Chen \& Burris (1990), os danos de secagem estão relacionados com a ruptura da membrana, com conseqüente aumento da condutividade elétrica e lixiviação de açúcares. Seyedin et al. (1984) estudando o efeito da temperatura de secagem na qualidade fisiológica das sementes, verificaram que a temperatura pode afetar a porcentagem de germinação e o vigor das plântulas, em sementes de milho. Esse efeito da secagem pode ser verificado imediatamente (efeito imediato), isto é, logo após a operação, ou somente se manifestará após um determinado período de armazenamento (efeito latente).

Diversas temperaturas de secagem de milho em espiga são encontradas na literatura, no entanto, segundo Cone et al. (1996), quando a temperatura de secagem é acima de $40^{\circ} \mathrm{C}$, algumas proteínas podem ser desnaturadas causando mudanças em suas propriedades. No entanto, Heter \& Burris (1989) destacaram a ausência de efeito negativo da secagem excessiva, com temperatura de $40^{\circ} \mathrm{C}$, na qualidade das sementes. No entanto, segundo Toledo (1978), sendo material sensível, a temperatura não deve ser superior a $32^{\circ} \mathrm{C}$, quando as sementes são colhidas com $30 \%$ de teor de água e quando o teor estiver próximo de $17-18 \%$, a temperatura poderá atingir até $42-43^{\circ} \mathrm{C}$.

Considerando os trabalhos existentes sobre a qualidade de sementes de milho doce, pode-se inferir que, de maneira geral, esses possuem qualidade inferior, possivelmente devido a sua maior suscetibilidade aos danos mecânicos e aos térmicos durante o processo de secagem. Devido a esses fatos é que a produção de sementes de milho doce necessita de maiores cuidados no decorrer de todas as fases, pois, se uma das etapas for mal conduzida, pode-se comprometer a qualidade final das sementes, acarretando perdas econômicas. 
Devido a importância que o teor de água das sementes e a temperatura de secagem exercem na qualidade da semente, o presente estudo teve como objetivo avaliar a qualidade fisiológica de sementes de milho-doce BR400 (bt) em função do teor de água na colheita e da temperatura de secagem em espiga.

\section{MATERIAL E MÉTODOS}

O trabalho foi conduzido na área experimental da Faculdade de Ciências Agronômicas, FCA/UNESP, localizada no município de Botucatu-SP, a latitude $22^{\circ} 51^{\prime} \mathrm{S}$, longitude $48^{\circ} 26^{\prime} \mathrm{W}$ Grw e altitude de $740 \mathrm{~m}$. Segundo a classificação climática de Koeppen, o clima predominante na região é do tipo Cwa, o qual é caracterizado pelo clima tropical de altitude, com inverno seco e verão quente e chuvoso. A calagem e as adubações de semeadura e de cobertura foram feitas de acordo com recomendações encontradas em Cantarella \& Raij (1997). Foram utilizadas sementes de milho-doce, cultivar BR $400(b t)$ superdoce, desenvolvida pelo Programa de Melhoramento da Embrapa Milho e Sorgo, Sete Lagoas-MG, em conjunto com a Embrapa Hortaliças, Brasília-DF. A semeadura foi realizada em 12 de janeiro de 2000. Os tratos culturais e fitossanitários foram os normalmente utilizados para a cultura de milho comum. O delineamento experimental empregado foi o de blocos ao acaso com seis repetições, constituindo os tratamentos as épocas de colheitas das espigas e a temperatura do ar de secagem.

As colheitas das espigas, num total de seis, e designadas como 1C, 2C, 3C 4C, 5C e 6C, foram iniciadas após a maturidade fisiológica, detectada por meio de avaliação visual (camada negra). As espigas das cinco primeiras colheitas foram submetidas à secagem artificial e as da sexta foram secadas, naturalmente, no campo. Obtiveram-se nessas colheitas, 30 espigas por parcelas, que, após transportadas para o Departamento de Produção Vegetal - Setor Agricultura, foram despalhadas manualmente. Após o despalhamento, as espigas de cada uma das cinco primeiras colheitas, foram separadas em duas porções, nas quais foram feitas amostragens para avaliar o teor de água na colheita. Em seguida, as duas porções, foram submetidas à secagem em estufa com ventilação forçada, uma a $30^{\circ} \mathrm{C}(\mathrm{T} 30)$ e a outra a $40^{\circ} \mathrm{C}(\mathrm{T} 40)$, até as sementes alcançarem teor de água entre 12 a $10 \%$. Após a secagem, processou-se a debulha manual da espiga e uma nova amostragem foi feita para avaliar o teor de água.

O teor de água das sementes, inicial e após a secagem de todas as colheitas, foi determinado em estufa elétrica, sem ventilação forçada, a $105 \pm 3^{\circ} \mathrm{C}$, durante 24 horas (Brasil,
1992). Tornou-se duas subamostras de 50 sementes, para cada repetição de campo, previamente pesadas em balança com precisão de $0,01 \mathrm{~g}$ (peso úmido) e após a secagem foram feitas novas pesagens (peso seco). As determinações do teor de água nas sementes foram feitas em base úmida $\{$ (PU-PS)/ PU $\}$, com os dados expressos em porcentagem.

Depois de secadas e debulhadas, as sementes foram embaladas (cada parcela separadamente) em sacos de papel, para serem armazenadas em condições ambientais normais de laboratório (Tmáx. $30^{\circ} \mathrm{C}$, Tmín. $18^{\circ} \mathrm{C}$ e Tméd. $24^{\circ} \mathrm{C}$ com $95 \%$ de URmáx, 49\% de URmín. e 79\% de URméd.). A avaliação da qualidade fisiológica das sementes foram realizadas antes e após o armazenamento, durante seis meses, utilizando-se os seguintes testes: germinação - foi executado de acordo com Brasil (1992), com duas subamostras de 50 sementes por repetição de campo, totalizando 600 sementes por tratamento. Utilizou-se como substrato, papel toalha para germinação (germitest), umedecido previamente com água destilada na proporção de 2,5 vezes o peso seco do papel e os rolos com as sementes foram acondicionados em sacos plásticos e mantidos em germinador, tipo câmara de crescimento, na temperatura de $25^{\circ} \mathrm{C}$. As contagens foram realizadas no quarto e sétimo dia após a semeadura. Para o cálculo da porcentagem de germinação foi utilizada a somatória do número de plântulas normais obtidas nas duas contagens realizadas; primeira contagem da germinação - foi realizado, avaliandose o número de plântulas normais no quarto dia após a semeadura; frio - foram utilizadas duas subamostras de 50 sementes por repetição de campo. Como substrato utilizou-se o papel toalha para germinação (germitest), umedecido previamente com água destilada na proporção de 2,5 vezes o peso seco do papel e os rolos com as sementes foram acondicionados em sacos de plásticos e mantidos no germinador, tipo câmara de crescimento, na temperatura de $10^{\circ} \mathrm{C}$ por sete dias; a seguir foram colocados na temperatura de $25^{\circ} \mathrm{C}$, onde permaneceram por quatro dias, após o qual se realizou a contagem de plântulas normais (Cícero \& Vieira, 1994); envelhecimento acelerado - foram utilizadas 150 sementes por repetição de campo, colocadas sobre uma tela de aço inox, em caixas plásticas do tipo gerbox modificado, contendo $40 \mathrm{ml}$ de água destilada. As caixas foram mantidas em câmara de envelhecimento a $42^{\circ} \mathrm{C}$ e por 72 horas (Araújo, 1999); a seguir 100 sementes foram colocadas para germinar em papel toalha (RP). Os rolos com as sementes (RP) foram acondicionados em sacos de plásticos e mantidos em germinador a $25^{\circ} \mathrm{C}$. A contagem foi realizada no quarto dia após a semeadura. Determinou-se o teor de água das 50 sementes restantes do teste de envelhecimento, com duas subamostras, pelo 
método da estufa $105 \pm 3^{\circ} \mathrm{C}$ por 24 horas (Brasil, 1992); emergência, índice de velocidade de emergência e matéria seca da parte aérea da plântula - foram utilizadas 100 sementes por repetição de campo. Cada repetição foi semeada em sulco de $5,0 \mathrm{~m}$ de comprimento, a profundidade de $2,5 \mathrm{~cm}$. Após a semeadura, o sulco foi coberto e irrigado toda vez que o solo mostrava-se seco. Após o início da emergência das plântulas, foram feitas contagens diárias, até a paralisação da emergência, sendo consideradas como emersas as plântulas que apresentavam crescimento de $1 \mathrm{~cm}$ da parte aérea. Com os dados obtidos foram feitos os cálculos do índice de velocidade de emergência (IVE) e da porcentagem de emergência das plântulas (Nakagawa, 1994). Após a última contagem da avaliação da porcentagem de emergência, as plântulas foram cortadas ao nível do solo, colocadas em sacos de papel e levadas à estufa com circulação de ar forçado, mantida a $\pm 60^{\circ} \mathrm{C}$, onde permaneceram até atingirem peso constante. Após a secagem, o material foi pesado em balança com precisão de 0,01g. O peso obtido foi dividido pelo número de plântulas e resultou no peso médio da matéria seca por plântula, de cada repetição (Nakagawa, 1994); condutividade elétrica - foram utilizadas duas subamostras de 25 sementes por repetição de campo. Cada subamostra de 25 sementes foi previamente pesada com balança de precisão de $0,01 \mathrm{~g}$ e colocada em um copo plástico $(200 \mathrm{ml})$, adicionado-se $75 \mathrm{ml}$ de água destilada (com condutividade elétrica $\leq 2 \mu \mathrm{Scm}^{-1}$ ) e mantendo-se no ambiente com temperatura constante de $25^{\circ} \mathrm{C}$, durante 24 horas, devidamente coberto com saco de polietileno. Após o período estabelecido, as amostras foram retiradas e submetidas a uma suave agitação e efetuada a leitura da condutividade elétrica da solução de embebição, em condutivímetro CD-2P, modelo Digimed, sendo os resultados expressos em $\mu \mathrm{Scm}^{-1} \mathrm{~g}^{-1}$; avaliação dos nutrientes lixiviados - após a leitura da condutividade elétrica, fez-se uma amostra homogênea das duas subamostras, retirando-se uma alíquota e colocando-a em vidro tipo âmbar, com capacidade de $75 \mathrm{ml}$, para realizar as leituras das quantidades de nutrientes lixiviados. A determinação dos teores de magnésio, potássio, cálcio e sódio, foi feita de forma direta por absorção atômica. Após a determinação dos teores de $\mathrm{Mg}, \mathrm{K}, \mathrm{Ca}$ e $\mathrm{Na}$, foi feito o cálculo para se obter a quantidade do nutriente em $\mathrm{mg} / \mathrm{kg}$ de semente.

A análise estatística foi feita em esquema fatorial $5 \times 2$ com um tratamento adicional (testemunha), utilizando-se o software Statistical Analyses System (SAS, 1993). Os dados originais obtidos em porcentagem foram transformados em arco seno da raiz quadrada da porcentagem dividida por 100, $\mathrm{Y}=\left[\operatorname{arcsen} *(\mathrm{x} / 100)^{1 / 2}\right]$, exceção para o teor de $\mathrm{Mg}$ cujos dados foram transformados em $\left[(\mathrm{x}+0,5)^{1 / 2}\right]$. As médias foram comparadas pelo teste Tukey ao nível de 5\% de probabilidade. As médias das tabelas são os valores originais.

\section{RESULTADOS E DISCUSSÃO}

Observa-se na Tabela 1 que a variação do teor de água entre a primeira colheita e a última foi de 34,8 a $11,1 \%$, com uma diferença de $23,7 \%$ do teor de água na semente entre a primeira colheita (1C) com secagem artificial até a última colheita (6C) com secagem natural.

TABELA 1. Relação dos tratamentos de sementes de milho-doce com os respectivos dias de colheita, após o florescimento, teor de água na colheita e após a secagem a 30 e a $40^{\circ} \mathrm{C}$.

\begin{tabular}{cccccc}
\hline \multirow{2}{*}{ Tratamento } & \multirow{2}{*}{ CDAF } & TAC & \multicolumn{4}{c}{ TAS } \\
\cline { 4 - 6 } & & & $30^{\circ} \mathrm{C}$ & $40^{\circ} \mathrm{C}$ & Ambiente \\
\hline \multirow{2}{*}{$1 \mathrm{C}$} & 58 & 34,8 & $\mathrm{X}$ & $\mathrm{X}$ & - \\
$2 \mathrm{C}$ & 71 & 19,3 & $\mathrm{X}$ & $\mathrm{X}$ & - \\
$3 \mathrm{C}$ & 78 & 17,5 & $\mathrm{X}$ & $\mathrm{X}$ & - \\
$4 \mathrm{C}$ & 85 & 15,6 & $\mathrm{X}$ & $\mathrm{X}$ & - \\
$5 \mathrm{C}$ & 91 & 14,7 & $\mathrm{X}$ & $\mathrm{X}$ & - \\
$6 \mathrm{C}$ & 98 & 11,1 & - & - & 11,1 \\
\hline
\end{tabular}

Florescimento $=54$ dias após a semeadura

$\mathbf{C P A F}=$ colheita-dias após o florescimento; $\mathbf{T A C}=$ teor de água na colheita; $\mathbf{T A S}=$ teor de água após a secagem a temperatura.

Os valores médios de temperatura máxima, mínima e média do ar e a precipitação pluvial total ocorridos sete dias antes da primeira colheita (1C) e entre as colheitas (Figura 1), mostram que as condições climáticas foram favoráveis para a obtenção das sementes, considerando a baixa precipitação e as temperaturas não elevadas.

Após a secagem artificial, as sementes apresentaram teor de água entre 11 e $12 \%$. Esse valor foi semelhante ao da última colheita, com secagem no campo. Pelos valores do teor de água das sementes nota-se que a operação de secagem reduziu o teor de água a níveis considerados adequados para o armazenamento, em condições normais.

Antes do armazenamento comparou-se, por meio dos valores de " $F$ " da análise de variância, as avaliações da qualidade fisiológica das sementes, colhidas em espiga com teores de água entre $35 \%(1 \mathrm{C})$ e $15 \%(5 \mathrm{C})$ e submetidas à secagem nas espigas com temperaturas de 30 e $40^{\circ} \mathrm{C}$. Verifica-se, nas Tabelas 2 e 3, que apenas alguns testes de vigor mostraram significância (envelhecimento acelerado, primeira con- 


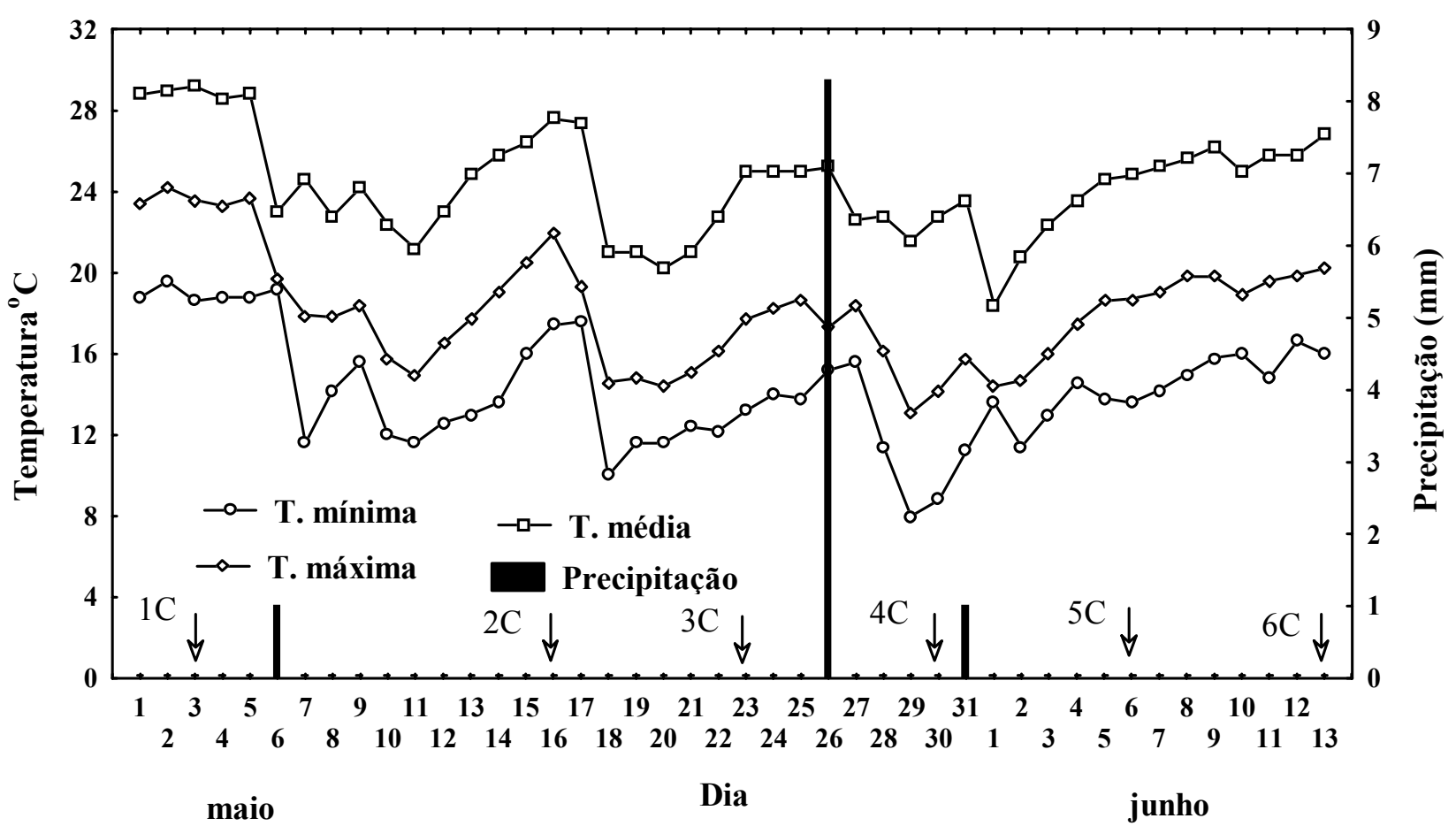

FIG. 1. Dados de precipitação pluvial e de temperaturas máximas, mínimas e média do ar, na época da colheita de sementes de milho-doce da cultivar BR400 (bt).

TABELA 2. Valores médios da emergência das plântulas em campo (EP), germinação (G), teste de frio (Frio), envelhecimento acelerado (EA), índice de velocidade de emergência (IVE), matéria seca de plântulas (MS) de sementes de milho-doce BR400 (bt), de seis colheitas, sendo cinco (1C a 5C) com secagem das espigas em duas temperaturas e uma (6C) com secagem no campo. Avaliações feitas antes do armazenamento. Botucatu, 2001.

\begin{tabular}{|c|c|c|c|c|c|c|c|}
\hline \multirow{3}{*}{$\begin{array}{c}\text { Tratamentos e teor } \\
\text { de água na colheita (\%) }\end{array}$} & \multirow{2}{*}{ EP } & \multirow{2}{*}{ G } & \multirow{2}{*}{ Frio } & \multicolumn{2}{|c|}{ EA $(\%)$} & \multirow{3}{*}{ IVE } & \multirow{3}{*}{$\begin{array}{c}\text { MS } \\
\text { g/plantas }\end{array}$} \\
\hline & & & & $30^{\circ} \mathrm{C}$ & \multirow[t]{2}{*}{$40^{\circ} \mathrm{C}$} & & \\
\hline & ……........... & $\ldots \ldots \ldots$ & ......... & . & & & \\
\hline $1 C-34,8$ & $93 \mathrm{a}^{1}$ & $92 \mathrm{a}$ & $79 a$ & $84 a b^{2}$ & $85 \mathrm{a} \mathrm{A}$ & $16,62 \mathrm{a}$ & $0,075 \mathrm{a}$ \\
\hline $2 C-19,3$ & $93 \mathrm{a}$ & $94 \mathrm{a}$ & $76 \mathrm{a}$ & $86 \mathrm{a} \mathrm{A}$ & 74 b B & $17,11 \mathrm{a}$ & $0,081 \mathrm{a}$ \\
\hline $3 C-17,5$ & $94 \mathrm{a}$ & $94 \mathrm{a}$ & $71 \mathrm{a}$ & 81 b c A & $82 \mathrm{a} b \mathrm{~A}$ & $16,06 \mathrm{a}$ & $0,095 \mathrm{a}$ \\
\hline $4 C-15,6$ & $92 \mathrm{a}$ & $92 \mathrm{a}$ & $72 \mathrm{a}$ & $82 \mathrm{bc} \mathrm{A}$ & $82 \mathrm{a} \mathrm{b} \mathrm{A}$ & $17,15 \mathrm{a}$ & $0,097 \mathrm{a}$ \\
\hline $5 C-14,7$ & $97 \mathrm{a}$ & $92 \mathrm{a}$ & $74 a$ & 73 c B & $82 \mathrm{a} \mathrm{b} \mathrm{A}$ & $16,73 \mathrm{a}$ & $0,082 \mathrm{a}$ \\
\hline Média $30^{\circ} \mathrm{C}$ & $94 \mathrm{~A}^{3}$ & $94 \mathrm{~A}$ & $75 \mathrm{~A}$ & & & $16,69 \mathrm{~A}$ & $0,091 \mathrm{~A}$ \\
\hline Média $40^{\circ} \mathrm{C}$ & $93 \mathrm{~A}$ & $92 \mathrm{~B}$ & $74 \mathrm{~A}$ & & & $16,77 \mathrm{~A}$ & $0,081 \mathrm{~B}$ \\
\hline Média fatorial & $94 \mathrm{X}^{4}$ & $93 \mathrm{X}$ & $75 \mathrm{X}$ & & & $16,73 X$ & $0,086 \mathrm{X}$ \\
\hline Adicional (6C) 11,1 & $88 \mathrm{X}$ & $93 X$ & $69 X$ & & & $17,12 \mathrm{X}$ & $0,081 X$ \\
\hline CV \% & 9,92 & 5,19 & 8,38 & & & 9,36 & 11,39 \\
\hline
\end{tabular}

${ }^{1} \mathrm{e}^{2}$ Médias seguidas pelas mesmas letras minúsculas, na coluna e maiúsculas na linha, não diferem entre si, pelo teste Tukey, a $5 \%$.

${ }^{3} \mathrm{e}^{4}$ Médias seguidas pelas mesmas letras na coluna, não diferem entre si, pelo teste Tukey, a 5\%. 
TABELA 3. Valores médios do vigor: primeira contagem da germinação (PCG), condutividade elétrica (CE), teores de magnésio $(\mathrm{Mg})$, cálcio $(\mathrm{Ca})$, sódio $(\mathrm{Na})$ e potássio $(\mathrm{K})$ lixiviados na solução do teste de condutividade elétrica, de sementes de milho-doce BR400 (bt), de seis colheitas, sendo cinco (1C a 5C) com secagem das espigas em duas temperaturas e uma (6C) com secagem no campo. Avaliações feitas antes do armazenamento. Botucatu, 2001.

\begin{tabular}{|c|c|c|c|c|c|c|c|}
\hline \multirow{3}{*}{$\begin{array}{l}\text { Tratamentos } \\
\text { (época colheita) }\end{array}$} & \multirow{3}{*}{$\begin{array}{l}\text { PCG } \\
(\%)\end{array}$} & \multirow{3}{*}{$\begin{array}{c}\mathrm{CE} \\
\mu \mathrm{S} / \mathrm{cm} / \mathrm{g}\end{array}$} & \multirow{2}{*}{$\mathrm{Mg}$} & \multirow{2}{*}{$\mathrm{Ca}$} & \multicolumn{2}{|c|}{$\mathrm{Na}$} & \multirow{2}{*}{$\mathrm{K}$} \\
\hline & & & & & $30^{\circ} \mathrm{C}$ & $40^{\circ} \mathrm{C}$ & \\
\hline & & & \multicolumn{5}{|c|}{ …................................... mg/kg de semente } \\
\hline $1 \mathrm{C}$ & $51 \mathrm{~b}^{1}$ & $20,92 \quad b$ & $0,25 \mathrm{~b}$ & $1,72 \mathrm{a} \mathrm{bc}$ & $2,18 \quad b^{2}$ & $2,83 \mathrm{~b} \mathrm{~A}$ & $467 \mathrm{a}$ \\
\hline $2 \mathrm{C}$ & $52 \mathrm{a} b$ & $20,09 \quad b$ & $0,38 \mathrm{ab}$ & $1,42 \mathrm{bc}$ & $2,30 \mathrm{a} \mathrm{b} \mathrm{A}$ & 1,79 c A & $403 \mathrm{a}$ \\
\hline $3 \mathrm{C}$ & $64 a$ & $21,45 \quad b$ & $0,72 \mathrm{a}$ & $1,92 \mathrm{a} \mathrm{b}$ & $2,34 \mathrm{a} \mathrm{b} \mathrm{A}$ & 1,77 & $486 \mathrm{a}$ \\
\hline $4 \mathrm{C}$ & $57 \mathrm{a} \mathrm{b}$ & $20,52 \quad b$ & $0,54 \mathrm{ab}$ & $1,28 \quad \mathrm{c}$ & 1,70 b A & 1,67 с A & $400 \mathrm{a}$ \\
\hline $5 \mathrm{C}$ & $64 \mathrm{a}$ & $26,66 \mathrm{a}$ & $0,63 \mathrm{ab}$ & $2,22 \mathrm{a}$ & $2,98 \mathrm{a} \mathrm{B}$ & $3,58 \mathrm{aA}$ & $421 \mathrm{a}$ \\
\hline Média $30^{\circ} \mathrm{C}$ & $59 \mathrm{~A}^{3}$ & $21,21 \mathrm{~A}$ & $0,52 \mathrm{~A}$ & $1,68 \mathrm{~A}$ & & & $455 \mathrm{~A}$ \\
\hline Média $40^{\circ} \mathrm{C}$ & $57 \mathrm{~A}$ & $20,64 \mathrm{~A}$ & $0,48 \mathrm{~A}$ & $1,76 \mathrm{~A}$ & & & $416 \mathrm{~A}$ \\
\hline Média fatorial & $58 X^{4}$ & $20,93 \mathrm{X}$ & $0,50 \mathrm{Y}$ & $1,72 \mathrm{Y}$ & & & $436 \mathrm{X}$ \\
\hline Adicional (6C) & $65 X$ & $23,42 \mathrm{X}$ & $0,87 X$ & $3,23 \mathrm{X}$ & & & $401 X$ \\
\hline CV $(\%)$ & 12,07 & 15,75 & 16,50 & 23,07 & & & 20,02 \\
\hline
\end{tabular}

$1 \mathrm{e}^{2}$ Médias seguidas pelas mesmas letras, minúsculas na coluna e maiúsculas na linha, não diferem entre si, pelo teste Tukey, a $5 \%$.

${ }^{3} \mathrm{e}^{4}$ Médias seguidas pelas mesmas letras na coluna, não diferem entre si, pelo teste Tukey, a $5 \%$.

tagem da germinação, condutividade elétrica e teores de $\mathrm{Na}$ ). Mas, de acordo com Carvalho \& Nakagawa (2000), um dos fatores que afetam a qualidade inicial das sementes são as condições climáticas, principalmente, se ocorrer uma maior precipitação. Segundo Popinigis (1977), a partir da maturidade fisiológica, o vigor e o poder germinativo das sementes decrescem devido a eventos relacionados ao processo de deterioração e em função das condições desfavoráveis do ambiente até a colheita.

Após o armazenamento os dados praticamente se confirmam, constatando-se diferenças significativas entre $1 \mathrm{C}$ e 5C apenas para os testes de frio, envelhecimento acelerado para $30^{\circ} \mathrm{C}$, condutividade elétrica, teores de $\mathrm{Mg}, \mathrm{Ca}$ e $\mathrm{Na}$, como pode ser observado com mais detalhes nas Tabelas $4 \mathrm{e}$ 5. Constata-se que os resultados de germinação na primeira e segunda épocas de colheita estão de acordo com os obtidos por Chen \& Burris (1990), que constataram que as porcentagens de germinação em sementes colhidas com teor de água abaixo de $40 \%$ não foram afetadas pela temperatura de secagem, quando essa for menor do que $45^{\circ} \mathrm{C}$. Borowski et al. (1991) também não detectaram diferenças significativas nos resultados de porcentagem de germinação entre colheitas com diferentes teores de água em cultivares de milho-doce $(\operatorname{sh} 2)$.

Verifica-se que a secagem artificial, tanto a 30 como a $40^{\circ} \mathrm{C}$, não afetou a qualidade das sementes, mesmo quando essas apresentaram teor de água mais elevado (Tabelas $2 \mathrm{e}$ 5). Como exceção tem-se o resultado dos testes de germinação, matéria seca de plântulas (diferença siginificativa nas médias entre 30 e $40^{\circ} \mathrm{C}$, nas Tabelas 2 e 3), envelhecimento acelerado (Tabela 2 e 4), teores de sódio (Tabela 3 e 5), condutividade elétrica (Tabela 5) e teores de magnésio e cálcio (Tabela 5) com efeitos significativos de interação entre colheita e temperatura. Analisando-se os resultados, observa-se por estes testes que o vigor das sementes foi afetado significativamente pelas colheitas e pelas temperaturas de secagem. Analisando-se os resultados do envelhecimento acelerado, constatou-se que houve influência negativa da temperatura de $40^{\circ} \mathrm{C}$ nas sementes colhidas com 19,3\% (2C); já pelos resultados dos lixiviados. Esta influência negativa foi detectada nos teores de água nas sementes de $34,8 \%$ (1C) e $14,7 \%$ (5C) para $40^{\circ} \mathrm{C}$ e de $17,5 \%$ (3C) para $30^{\circ} \mathrm{C}$. Para as demais colheitas, não houve efeito prejudicial das temperaturas de secagem utilizadas. Estes resultados confirmam, parcialmente, as conclusões de Knittle \& Burris (1976), que observaram que o vigor das sementes é dependente da época de colheita e que sementes de milho com teor de água na faixa de $32 \%$ a $38 \%$, apresentaram maior vigor.

Nos testes realizados antes do armazenamento verificase, nas Tabelas 2 e 3, que a sexta colheita (6C), com sementes secas no campo, não diferiram estatisticamente das colheitas realizadas com teor de água nas sementes mais elevado e sub- 
TABELA 4. Valores médios da emergência das plântulas em campo (EP), germinação (G), teste de frio (Frio), envelhecimento acelerado (EA), índice de velocidade de emergência (IVE), matéria seca de plântulas (MS) de sementes de milho-doce BR400 (bt), de seis colheitas, sendo cinco (1C a 5C) com secagem das espigas em duas temperaturas e uma colheita (6C) com secagem no campo. Avaliações feitas após seis meses de armazenamento. Botucatu, 2001.

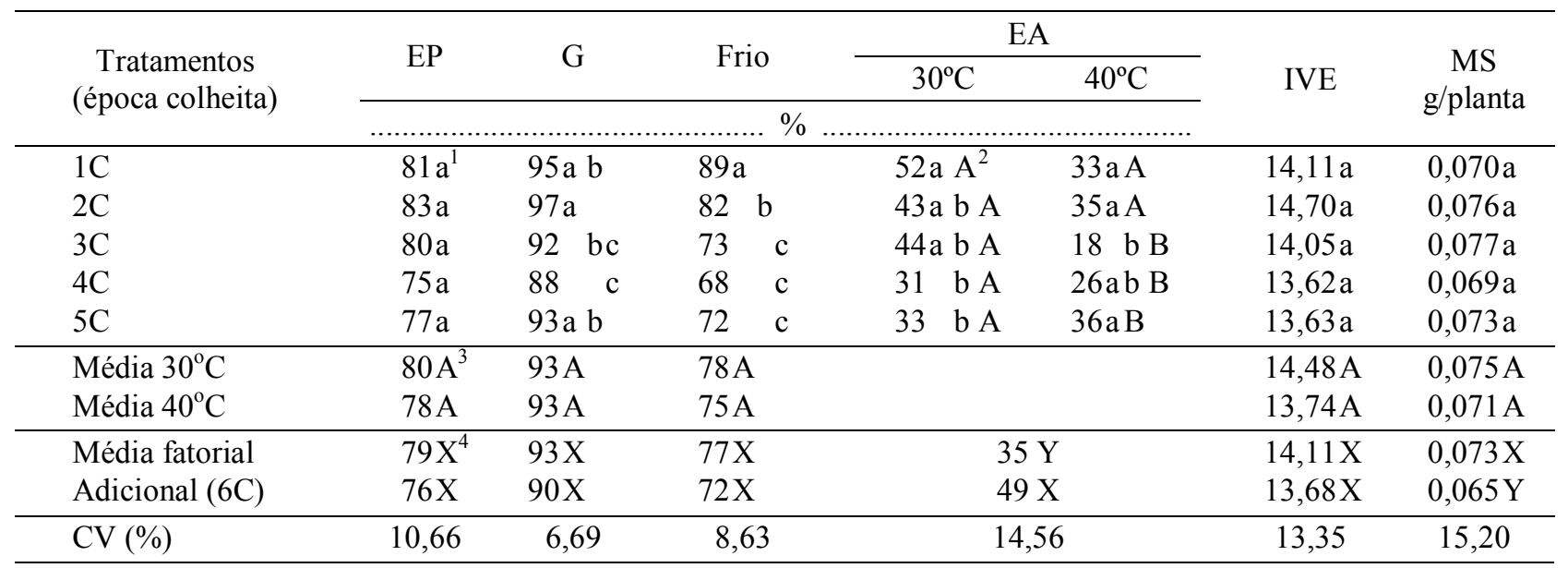

${ }^{1} \mathrm{e}^{2}$ Médias seguidas pelas mesmas letras, minúsculas na coluna e maiúsculas na linha, não diferem entre si, pelo teste Tukey, a $5 \%$.

${ }^{3} \mathrm{e}^{4}$ Médias seguidas pelas mesmas letras na coluna, não diferem entre si, pelo teste Tukey, a $5 \%$.

metidas a secagem artificial, com exceção dos testes de teores de magnésio, cálcio e sódio.

Para os testes realizados após o armazenamento constatou-se, nas Tabelas 4 e 5 , que não houveram diferenças significativas para as sementes colhidas e secas artificialmente $(1 \mathrm{C}$ e 5C) e as secas no campo (6C), exceto para os testes de envelhecimento acelerado, matéria seca de plântula, condutividade elétrica e teor de sódio. Segundo Wann (1986), lixiviados liberados na água de embebição podem indicar o nível do vigor das sementes. Todavia na presente avaliação não se mostraram consistentes com os resultados dos demais testes. Os valores de condutividade elétrica e a concentração de potássio, cálcio e magnésio, segundo Fessel et al. (2000), possibilitam detectar o processo inicial de deterioração da semente pela perda da integridade da membrana. Herter \& Burris (1989) observaram que temperaturas inferiores a $40^{\circ} \mathrm{C}$ não promovem efeitos negativos na qualidade de sementes secadas em espigas.

Os resultados evidenciaram que os prováveis danos causados pela temperatura de secagem estão relacionados com o teor de água inicial das sementes, pois, dependendo dele, alguns testes apresentaram uma diferenciação quanto a qualidade fisiológica das sementes, em relação a temperatura de secagem utilizada.

Os resultados de germinação e de vigor possibilitam que se realize colheita de sementes da cultivar BR $400(b t)$ com maior teor de água, seguindo-se da secagem artificial na espiga.

Não houve efeitos significativos para a maioria dos fatores estudados: colheita com diferentes teores de água e temperatura de secagem.

Os resultados indicaram que pode ter ocorrido uma interferência na qualidade fisiológica das sementes em função do tipo de secagem utilizadas, se artificial (dependendo da temperatura) ou natural.

Os valores obtidos nos testes de avaliação da qualidade das sementes, após seis meses de armazenamento, mostraram que apesar de ter havido a sensibilidade de alguns deles em detectar o efeito diferenciado da temperatura no vigor das sementes, em função do teor inicial de água (na colheita), esse efeito não foi o bastante pronunciado para ocasionar diminuição na qualidade das sementes.

Os resultados do efeito prejudicial imediato da temperatura demonstrados por alguns testes não apresentaram uma congruência entre eles, isto é, foram demasiadamente contrastantes, demonstrando que apesar destes detectarem diferenças entre a qualidade fisiológica das sementes entre as temperatura de secagem, observou-se que essas foram pequenas.

Após seis meses de armazenamento, o efeito latente da temperatura de secagem foi detectado por um maior número de testes em relação as avaliações iniciais, porém, verificou- 


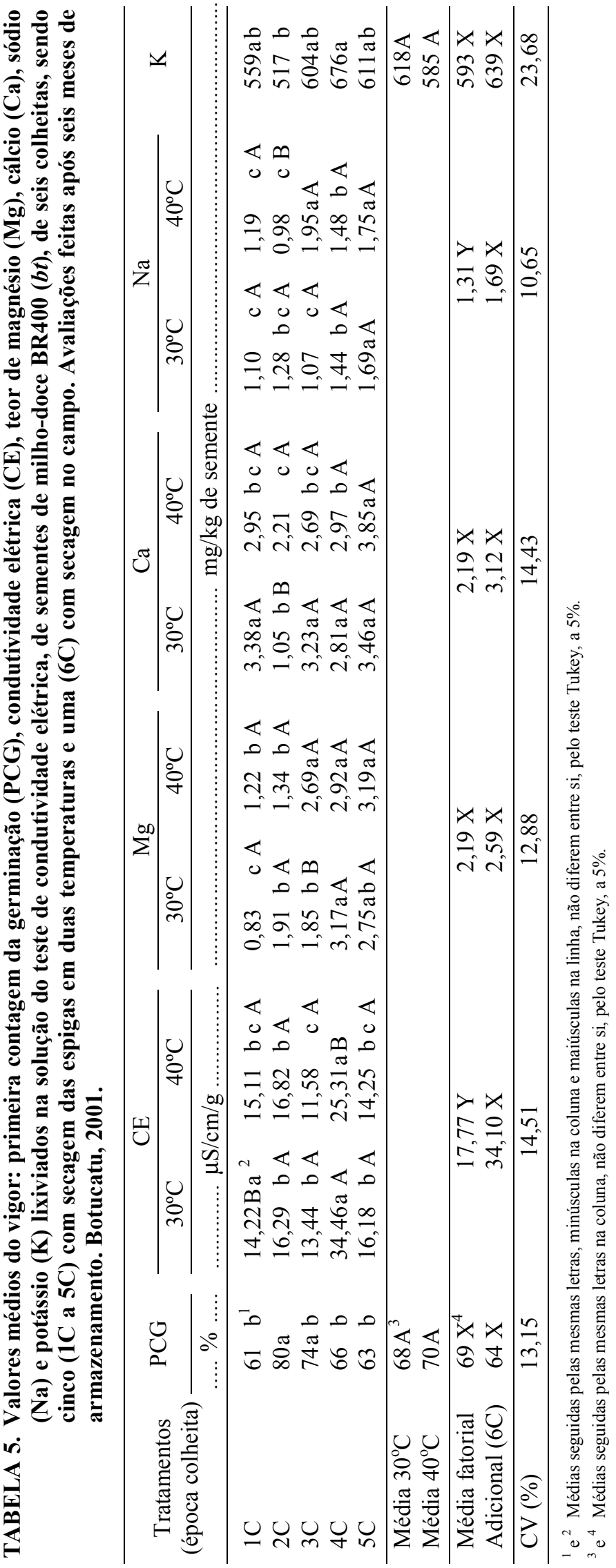

se, principalmente, pela quantidade de lixiviado que esse efeito foi mínimo, apesar desses detectarem o efeito prejudicial da temperatura de secagem, o vigor das sementes foram semelhantes entre as colheitas efetuadas.

\section{CONCLUSÕES}

Observou-se que as sementes de milho-doce da cultivar BR $400(b t)$ com teor de água igual a $35 \%$ ou menos, podem ser submetidas à secagem em espiga a temperatura de $30 \mathrm{ou}$ $40^{\circ} \mathrm{C}$ ou secadas naturalmente no campo, sem perdas significativas na sua qualidade fisiológica.

\section{REFERÊNCIAS}

ARAÚJO, E.F. Efeito da temperatura e umidade relativa do ar de secagem sobre a qualidade fisiológica e determinação do equilíbrio higroscópico de sementes de milho doce (Zea mays L.). Campos dos Goytacazes: CCTA/UENF, 1999. 128p. (Tese Doutorado)

BENNETT, M.A.; WATERS-JR, L. \& CURMER, J.H. Kernel maturity, seed size, and seed hydration effects on the seed quality of a sweet corn inbred. Journal of American Society Horticultural Science, Alexandria, v.113, n.1 p.348-353, 1988.

BOROWSKI, A.M.; FRITZ, V.A. \& WATERS-JR, L. Seed maturity influences germination and vigor of two shrunken 2 sweet corn hybrids. Journal of American Society. Horticultural Science, Alexandria, v.116, n.3, p.401-404, 1991.

BRASIL. Ministério da Agricultura e Reforma Agrária Regras para análise de sementes. Brasilia: SNAD/DNDV/CLAV, 1992. $365 \mathrm{p}$.

CAMERON, J.W. \& TEAS, H.J. Carbohydrates relationships in developing and mature endosperms of brittle and related maize genotypes. American Journal Botanic, Bronx, v.41, n.1, p.50$55,1954$.

CANTARELLA, H. \& RAIJ, B.van. Milho verde e milho doce. In: RAIJ, B.van; CANTARELlA, H.; QUAGGIO, J.A. \& FURLANI, A.M.C. (eds.). Recomendacões de adubação e calagem para o Estado de São Paulo. 2.ed. Campinas: Instituto Agronômico/Fundação IAC, 1996. p.64-65. (Boletim Técnico, 100).

CARVALHO, N.M. \& NAKAGAWA, L. Sementes: ciência, tecnologia e produção. Jaboticabal: FUNEP, 2000. 588p.

CHEN, Y.G. \& BURRIS, J.S. Role of carbohydrate in desiccation tolerance and membrane behavior in maturing maize seed. Crop Science, Madisom, v.30, n.3, p.971-975, 1990.

CHURCHILL, G.A. \& ANDREW, R.W. Effects of two maize endosperm mutants on kernel maturity carbohydrates and germination. Crop Science, Madison, v.24, n.1, p.76-81, 1984.

CÍCERO, S.M. \& VIEIRA, R.D. Teste de frio. In: VIEIRA, R.D. \& CARVALHO, N.M. (eds.). Testes de vigor em sementes. Jaboticabal: FUNEP/UNESP, 1994. p.151-164. 
CONE, J.W.; GELDER, A.H. \& MARVIN, H.J.P. Influence of drying method and ageing on chemical and physical properties and in vitro degradation characteristics of grass and maize samples. Journal of Agricultural Science, Cambridge, v.126, n.1, p.714, 1996.

DOUGLASS, S.K ; JUVIK, J.A. \& SPLITTSTOESSER, W.E. Sweet corn seedling emergence and variation in kernel carbohydrate reserves. Seed Science and Technology, Zürich, v.21, n.3, p.433-445, 1993.

FESSEL, S.A.; VIEIRA, R.D. \& CRUZ, M.C.P. Composição mineral e condutividade elétrica de soluções de embebição de sementes de milho armazenadas em diferentes temperaturas In: CONGRESSO NACIONAL DE MILHO E SORGO, 23 , Uberlândia, 2000. Resumos. Uberlândia: SBMS, 2000. p.294.

GAMA, E.E.G. Melhoramento de milhos especiais. In: SIMPÓSIO SOBRE ATUALIZAÇÃO EM GENÉTICA E MELHORAMENTO DE PLANTAS, 1, Lavras, 1997. Anais. Lavras: UFLA, 1997. p.231-271.

HERTER, V. \& BURRIS, J.S. Effect of drying rate and temperature on drying injury of corn seed. Canadian Journal of Plant Science, Ottawa, v.69, n.2, p.763-774, 1989.

KNITTLE, K.H. \& BURRIS, J.S. Effect of kernel maturation on subsequent seedling vigor. Crop Science, Madison, v.16, n.6, p.851-855, 1976

McDONALD, M.B.; SULLIVAN, J. \& LAWER, M.J. The pathway of water uptake in maize seeds. Seed Science and Technology, Zürich, v.22, n.1, p.79-90, 1994.
NAKAGAWA, J. Teste de vigor baseados na avaliação das plântulas. In: VIEIRA, R.D. \& CARVALHO, N.M. (eds.). Testes de vigor em sementes. Jaboticabal: FUNEP/UNESP, 1994. p.49-85.

NAVRATIL, R.J. \& BURRIS, The effect of drying temperature on corn seed quality. Canadian Journal of Plant Science, Ottawa, v.64, n.1, p.487-496, 1984.

POPINIGIS, F. Fisiologia da semente. Brasília: AGIPLAN, 1977. $289 \mathrm{p}$.

SEYEDIN, N.; BURRIS; J.S. \& FLYNN, T.E. Physiological studies on the effects of drying temperature on corn seed quality. Canadian Journal of Plant Science, Ottawa, v.64, n.1, p.497504, 1984.

TOLEDO, F.F. Tecnologia das sementes. In: PATERNIANI, E. \& VIÉGAS, G.P. (eds.). Melhoramento e produção do milho. Campinas: Fundação Cargill, 1978. v.2, p.713-761.

VYN, T.J. \& MOES, J. Breakage susceptibility of corn kernels in relation to crop management under long growing season conditions. Agronomy Journal, Madison., v.80, n.6, p.915920, 1988.

WANN, E.V. Leaching of metabolites during imbibition of sweet corn seed of different endosperm genotypes. Crop Science, Madson, v.26, n.2, p.731-733, 1986.

WATERS-JR, L. \& BLANCHETTE, B. Prediction of sweet corn field emergence by conductivity and cold tests. Journal of American Society Horticultural Science, Alexandria, v.108, n.5, p.778-781, 1983. 